\title{
HMGB1 a-Box Reverses Brain Edema and Deterioration of Neurological Function in a Traumatic Brain Injury Mouse Model
}

\author{
Lijun Yang ${ }^{a, b}$ Feng Wang ${ }^{a}$ Liang Yang ${ }^{a}$ Yunchao Yuan ${ }^{a} \quad$ Yan Chen ${ }^{a}$ \\ Gengshen Zhanga Zhenzeng Fana \\ aDepartment of Neurosurgery, The Second Hospital of Hebei Medical University, Shijiazhuang, ${ }^{\text {bHebei }}$ \\ Medical University Clinical Medicine Postdoctoral Mobile Station, Shijiazhuang, China
}

\section{Key Words}

Traumatic brain injury (TBI) • High mobility group box-1 (HMGB1)

\begin{abstract}
Background/Aims: Traumatic brain injury (TBI) is a complex neurological injury in young adults lacking effective treatment. Emerging evidences suggest that inflammation contributes to the secondary brain injury following TBI, including breakdown of the blood brain barrier (BBB), subsequent edema and neurological deterioration. High mobility group box-1 (HMGB1) has been identified as a key cytokine in the inflammation reaction following TBI. Here, we investigated the therapeutic efficacy of HMGB1 A-box fragment, an antagonist competing with full-length HMGB1 for receptor binding, against TBI. Methods: TBI was induced by controlled cortical impact (CCI) in adult male mice. HMGB1 A-box fragment was given intravenously at $2 \mathrm{mg} / \mathrm{kg} /$ day for 3 days after CCI. HMGB1 A-box-treated CCI mice were compared with saline-treated CCI mice and sham mice in terms of BBB disruption evaluated by Evan's blue extravasation, brain edema by brain water content, cell death by propidium iodide staining, inflammation by Western blot and ELISA assay for cytokine productions, as well as neurological functions by the modified Neurological Severity Score, wire grip and beam walking tests. Results: HMGB1 A-box reversed brain damages in the mice following TBI. It significantly reduced brain edema by protecting integrity of the $\mathrm{BBB}$, ameliorated cell degeneration, and decreased expression of pro-inflammatory cytokines released in injured brain after TBI. These cellular and molecular effects were accompanied by improved behavioral performance in TBI mice. Notably, HMGB1 A-box blocked IL-1 $\beta$-induced HMGB1 release, and preferentially attenuated TLR4, Myd88 and P65 in astrocyte cultures. Conclusion: Our data suggest that HMGB1 is involved in CCI-induced TBI, which can be inhibited by HMGB1 A-box fragment. Therefore, HMGB1 A-box fragment may have therapeutic potential for the secondary brain damages in TBI.




\section{Introduction}

Traumatic brain injury (TBI) is a complex neurological injury with high rates of mortality, morbidity and disability in young adults [1]. The direct trauma and lack of cerebral blood flow to the injured tissue immediately following TBI cause neuron death. Additionally, these acute damages, if accompanied by disruption of blood brain barrier (BBB), cerebral ischemia, edema and high intracranial pressure, will incur a poor prognosis [2]. However, effective therapies to control brain damages following TBI are lacking, partly due to the poorly understood mechanisms underlying acute and secondary effects of TBI.

Emerging evidences suggest that inflammation plays essential roles in breakdown of the $\mathrm{BBB}$, subsequent edema and neurological deterioration after TBI $[3,4]$. For instance, increased cerebrospinal fluid levels of the pro-inflammatory cytokines, including interleukin (IL)-1 $\beta$, IL-6 and tumor necrosis factor (TNF)- $\alpha$, correlate with cerebral edema and neurological deterioration after TBI [5]. Moreover, various inhibitors of these pro-inflammatory factors have been evaluated for their potential effects in TBI [6-8].

High mobility group box-1 (HMGB1) is an architectural chromatin-binding factor involved in the maintenance of nucleosome structure and the regulation of gene transcription. It exhibits cytokine activity once released into the extracellular space from immune and non-immune cells in response to various stimuli. Extracellular HMGB1 contributes to the pathogenesis of numerous chronic inflammatory and autoimmune diseases, including trauma and ischemia [9]. Through binding to its receptors, toll-like receptor (TLR) subtypes $2 / 4$ or receptors for advanced glycation end products (RAGE), HMGB1 provokes a cascade of events to exacerbate inflammation $[9,10]$. HMGB1 consists of two DNA binding domains, named A and B boxes, and an acidic C-terminus $[9,10]$. HMGB1 B box has been mapped as a pro-inflammatory domain [10], while A-box of HMGB1 contains binding sites for HMGB1 receptors. Recombinant HMGB1 A-box, as an antagonist competing with full-length HMGB1 for receptor binding, was shown to attenuate the pro-inflammatory effect of the full length HMGB1 and the B box peptide $[9,11]$.

In this study, we examined the protective effects of HMGB1 A-box fragment on TBI mouse model, established with controlled cortical impact (CCI). We demonstrated that HMGB1 A-box fragment remarkably ameliorated the BBB breakdown and brain edema induced by $\mathrm{CCI}$, and these effects were likely associated with the decrease in expressions of inflammation-related factors. Meanwhile, these benefits were accompanied by improved neurological functions. Our data suggest that HMGB1 A-box fragment may have therapeutic potential for TBI.

\section{Materials and Methods}

Animal

All animal care and experimental protocols were approved by Animal Care and Research Committee in Hebei Medical University. Male C57/BL6 mice (3-4 months old), weighed between 22 and 26 g, were used in this study. All mice were housed in an environment with stable temperature of $22 \pm 2^{\circ} \mathrm{C}$, relative humidity of 45-75\%, and with $12 \mathrm{~h}$ light-dark cycle. Additionally, water and food were provided ad libitum.

\section{Recombinant HMGB1 A-box protein}

Recombinant HMGB1 A-box was prepared as described previously [12]. Briefly, competence coli bacillus M15 (Dingguo Biotech, Beijing, China) was transfected with a pQE-80L/DHFR vector containing HMGB1 A-box gene, and protein expression was induced with isopropylthio- $\beta$-D-galactoside. The product (HMGB1 A-box) was purified using His-tagged affinity column (Invitrogen/Thermo Fisher Scientific, U.S.A.), and was subsequently passed through a polymyxin B column (Pierce Chemical, Rockford, IL, U.S.A.) to reduce the lipopolysaccharide content. The purity of recombinant HMGB1 A-box was verified by SDS-PAGE and Coomassie blue staining analysis. Protein concentration was determined by the Bio-Rad Protein Assay (Bio-Rad Laboratories, Hercules, CA, U.S.A.) according to the protocol provided by manufacturer.

\section{KARGER}


Controlled cortical impact (CCI) model of TBI

A TBI model was produced with CCI injury as previously described [13]. Mice were anesthetized with isoflurane $5 \%$ induction; $2 \%$ maintenance), and secured in a stereotaxic frame, and subjected to mechanical ventilation. Utilizing aseptic technique, a right-sided 4-mm craniotomy at $1.0 \mathrm{~mm}$ posterior to bregma was performed. With an electromagnetic stereotaxic impactor (Leica Biosystems Richmond, formerly MyNeuroLab, Richmond, IL), CCI was induced by the impactor perpendicular to the cortical surface at a depth of $1.0 \mathrm{~mm}$, at a velocity of $3.0-\mathrm{m} / \mathrm{sec}$, and with $100 \mathrm{~ms}$ contact. Immediately after injury, the bone flap was replaced, sealed with permanent cyanoacrylate-based fast-acting adhesive, and the skin incision was closed with nylon sutures. Duration of surgery was approximately $20 \pm 5$ mins. Sham controls were subjected to isoflurane anesthesia and craniotomy, but not CCI. A single dose of shortacting buprenorphine $(0.05 \mathrm{mg} / \mathrm{kg}$; subcutaneous injection) was administered by the end of the surgery to facilitate postoperative recovery. CCI group was divided into two subgroups, receiving intravenous injection of HMGB1 A-box at a dose of $2 \mathrm{mg} / \mathrm{kg} /$ day for 3 days after CCI, or receiving injection of the same volume of vehicle once per day for 3 days after CCI.

\section{Neurological functional evaluation}

Neurological motor measurement was performed using the modified Neurological Severity Score (mNSS) as described [14]. The mNSS is a composite index of motor, sensory, reflex, and balance tests. These tests were performed on all mice 1 day before and 6 days after CCI (Day 0 and Day 7 in the Fig. 1, respectively). All measurements were performed by observers blind to treatment. Briefly, this motor test (total score points 18 ) is based on 1) raising the mouse by tail and recording flexion (3 points), 2) walking on the floor ( 3 points), 3 ) sensory test ( 2 points), 4) balance beam tests ( 6 points), and absence of reflexes and abnormality of movements ( 4 points). Higher points represent the inability to perform the tasks or for the lack of a tested reflex. Levels of injury in animals are determined as severe (13-18 points), moderate (712 points) and mild (1-6 points).

\section{Wire grip test}

Motor test was performed as previously described [15]. Mice were gently grasped by the tail and placed on a $35 \mathrm{~cm}$ taut wire suspended between two upright wooden bars $50 \mathrm{~cm}$ above a padded table. Mice were held up to the wire, so that they can grip it with both front paws. Each animal was scored by the same experienced investigator. A six-point scoring system was used in which 0 indicates an animal's inability to remain on the wire for $30 \mathrm{~s}$; 1 indicates mouse holds on wire $30 \mathrm{~s}$, not both sets of paws on the wire; 2 indicates mouse holds on to the wire with all paws but not the tail; 3 indicates mouse uses its tail along with all paws without movement on the wire; 4 indicates mouse moves along the wire on all four paws plus tail; 5 indicates mouse ambulates down from one of the posts used to support the wire.

\section{Beam walking test}

The beam walking test was used to assess fine motor coordination and function by measuring the ability of the animals to traverse an elevated narrow beam as described previously [16]. The time for the mouse to cross the beam was recorded. 


\section{Evaluation of BBB leakage by Evan's blue (EB) extravasation}

BBB disruption was assessed as described before [17]. A 2\% Evans Blue solution in normal saline (4 $\mathrm{ml} / \mathrm{kg}$ of body weight) was injected intravenously. The dye was allowed to circulate for $2 \mathrm{~h}$. The mice were then transcardially perfused with $50 \mathrm{ml}$ ice-cold phosphate-buffered saline (PBS). The brain was removed and divided into right and left hemispheres, frozen in liquid nitrogen, and stored at $-80^{\circ} \mathrm{C}$. The samples were homogenized in 1, $100 \mu \mathrm{l}$ of PBS, sonicated, and centrifuged ( $30 \mathrm{~min}, 15,000 \mathrm{rcf}, 4^{\circ} \mathrm{C}$ ), then, the supernatant was collected in aliquots. An equal volume of $50 \%$ trichloroacetic acid was added into $500 \mu \mathrm{l}$ aliquot. The mixture was incubated overnight at $4^{\circ} \mathrm{C}$, then centrifuged $\left(30 \mathrm{~min}, 15,000 \mathrm{rcf}, 4^{\circ} \mathrm{C}\right)$. Evans Blue concentration was measured by spectrophotometer (Thermo Fischer Scientific Inc., U.S.A.) at $620 \mathrm{~nm}$, and was quantified according to a standard curve. The results are presented as $\mu \mathrm{g}$ Evans Blue stain per gram tissue.

\section{Measurement of plasmalemma permeability}

Propidium iodide (PI) is a 668 Da membrane-impermeable nucleic acid stain that emits bright red fluorescence when bound to RNA or DNA. PI uptake versus exclusion can be used to discriminate dead cells [18]. PI $(0.4 \mathrm{mg} / \mathrm{ml}, 100 \mu \mathrm{l})$ was administered intraperitoneally at $24 \mathrm{~h}$ after TBI. One hour later, the mice were deeply anesthetized and sacrificed. A series of eight $12 \mu \mathrm{m}$ thick sections were made with a distance of $200 \mu \mathrm{m}$ between adjacent sections from anterior to posterior hippocampus in each animal. Sections were fixed with $100 \%$ alcohol for $15 \mathrm{~min}$, and five visual fields of the injured area (200x) were randomly chosen to count the numbers of PI positive cells with stereology microscope (Ludl Electronic Product Ltd).

\section{Measurement of Edema (brain water content, BWC)}

BWC was measured with a drying method [19]. Briefly, the cerebral tissue was removed at various time after CCI, and the right and left hemispheres were separated along the midline. The wet weight of each hemisphere was measured. The tissues were then completely dried in an oven at $100^{\circ} \mathrm{C}$ for 5 days, and the dry weight of each hemisphere was recorded. The percentage of water content (\% water) was calculated according to the Elliott formula [20]: \%water = [(wet weight-dry weight $) /$ wet weight $] \times 100$.

\section{Western blot}

Protein from cortex was extracted and performed for standard western blot [21]. Primary antibodies included rabbit polyclonal anti-AQP4 antibody (1:500, Santa Cruz Biotechnology, Inc, Dallas, TX, USA), TLR4 (rabbit pAb, 1:400, Abcam, Cambridge, MA, USA), MMP-9 (Goat pAb, 1:200, Santa Cruz Biotechnology, USA), MMP-2 (rabbit pAb H-76, Santa Cruz Biotechnology, USA), MyD88 (rabbit pAb, Cell Signaling, Danvers, MA, USA), HMGB1 (rabbit pAb, Cell Signaling), NF-kB p65 (Rabbit pAb, Abcam, USA), Lamin B (Rabbit pAb, Abcam, USA), GAPDH (Mouse pAb1:10, 000, Abcam, USA) and anti-actin (mouse pAb, Abcam, USA). Antibody-protein complexes were visualized by chemiluminescent reagents. Optical density of respective protein band was analyzed with Quantity One (Bio-Rid, Hercules, CA, USA) and normalized with loading control (GAPDH or actin).

\section{ELISA assay of TNF- $\alpha$ and IL-1 $\beta$}

TNF- $\alpha$, IL-1 $\beta$ and IL- 6 in astrocyte cultures were measured using ELISA ready-SET-Go assay kits (eBioscience, San Diego, USA), according instruction provided by manufacturer. Protein level was expressed as $\mathrm{pg} / \mu \mathrm{g}$ of total proteins determined over an albumin standard curve.

\section{Primary astrocyte culture}

Primary astrocyte cultures were prepared as described previously [22] with minor modifications. The cerebral hemispheres of neonatal mice (P2) were dissected and transferred to ice-cold Hank's buffer, and the meninges were carefully removed. Tissues were then minced into $\sim 1 \mathrm{~mm}$ pieces, triturated, filtered through a $60 \mu \mathrm{m}$ nylon screen, and collected by centrifugation at $\sim 3,000 \mathrm{~g}$ for $5 \mathrm{~min}$. The cell pellets were dispersed with a pipette and resuspended in a medium containing $10 \%$ fetal bovine serum (FBS) in low glucose DMEM (Dulbecco's Modified Eagle's Medium, Thermo Fisher Inc, U.S.A.). After trituration, the cells were filtered through a $10 \mu \mathrm{m}$ screen and then plated into 6-well plates at a density of $2.5 \times 10^{5} \mathrm{cells} / \mathrm{cm}^{2}$, and cultured for about 10 days. The medium was replaced twice a week with 10\% FBS. Dibutyryl cAMP (d-cAMP, $0.15 \mathrm{mM}$, Sigma, St Louis, MO) was added to induce differentiation when the cells were grown to 95\% confluence. Prior to transfection or stimulation, Opti-MEM was replaced. Astrocytes were incubated for different time periods ranging from $1 \mathrm{~h}$ to $4 \mathrm{~h}$ depending on the experiment. 
Statistical analysis

Data are presented as mean \pm SEM. Statistical significance was determined by one-way ANOVA with Dunnett's or Tukey's post tests using the GraphPad Prism 5 software. Difference was considered statistically significant when $P$ value was less than 0.05 .

\section{Results}

\section{HMGB1 A-box improved neurological function in TBI mice}

To assess the effect of HMGB1 A-box on motor functions in TBI mice, mNSS score, wire grip test and beam walking test were performed. As shown in Fig. 1, significant deficits in mNSS score, wire grip test and beam walking test were observed in TBI mice. The most severe deficits occurred 1 day after injury, and the performance of TBI mice in these tests gradually recovered, but still significantly worse than sham mice from 1 to 3 days after CCI. The performance of the mice in motor and balance beam tests, instead of mNNS, recovered close to sham mice 7 days after CCI. Administration of HMGB1 A-box partially reversed these deficits, accelerating the recovery of neurological functions in TBI mice. Specifically, mNSS score in TBI mice was significantly reduced by HMGB1 A-box treatment 1, 2, 3 and 7 days after CCI (Fig. 1A). HMGB1 A-box improved wire grip scores 1, 2 and 3 days after CCI, even to similar level as sham-injured mice 7 days after surgery (Fig. 1B). Beam walking latency was also shortened by $15 \%$ after HMGB1 A-box treatment (Fig. 1C).

\section{HMGB1 A-box alleviated BBB disruption and brain edema in TBI mice}

We next examined the ability of HMGB1 A-box to prevent BBB leakage of Evans blue at 24 and $72 \mathrm{~h}$ after CCI. BBB damage was increased in the injured hemisphere of vehicletreated mice (Fig. 2A). Compared with vehicle treatment, HMGB1 A-box significant reduced Evans blue extravasation in injured hemisphere 24 and $72 \mathrm{~h}$ after CCI (Fig. 2A), indicating the efficacy of HMGB1 A-box in protecting BBB. To further support that HMGB1 A-box blocks BBB leakage, we used Western blot assay to determine the expression of proteins involved in the maintenance of BBB integrity, including zonula occludens-1 (ZO-1), claudin-5 and occludin, and examined whether these proteins in ipsilateral hemisphere of TBI mice were improved by HMGB1 A-box administration. We observed that CCI reduced the expression of ZO-1, claudin-5 and occludin in ipsilateral hemisphere 24 and $72 \mathrm{~h}$ after CCI (Fig. 2B). HMGB1 A-box induced a robust increase in the levels of ZO-1, claudin-5 and occludin compared with vehicletreated CCI mice (Fig. 2C, D, E).

As the damage of BBB may lead to brain edema, we next examined whether CCI induced brain edema, and whether HMGB1 A-box could reverse brain edema. As illustrated in

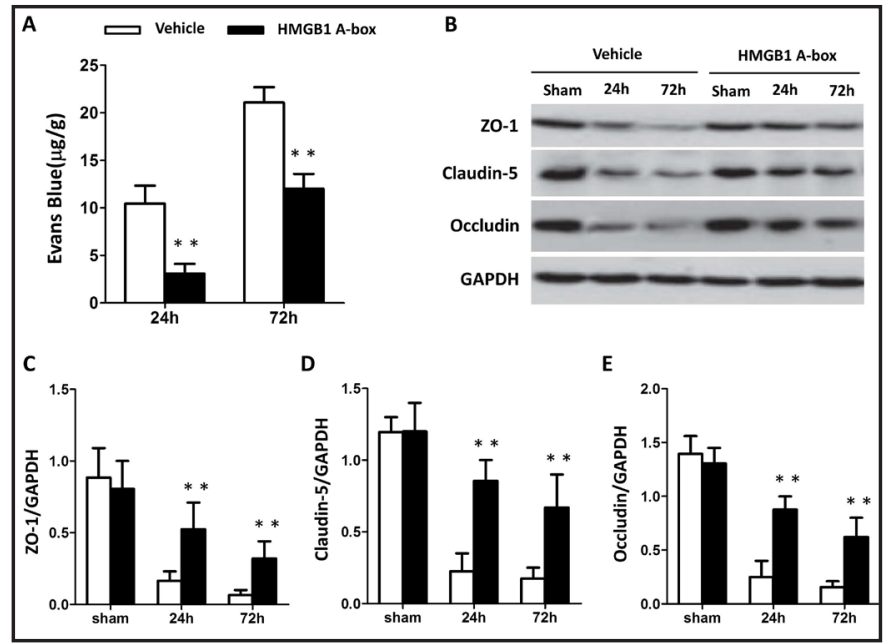

Fig 2. HMGB1 A-box improved BBB integrity in TBI. (A) HMGB1 A-box ( $2 \mathrm{mg} / \mathrm{Kg}$ ) significantly reduced Evans blue leakage into injured hemispheres, measured 24 and $72 \mathrm{~h}$ after CCI, respectively. (B) Representative picture of western blot assay of ZO-1, Claudin-5, and Occludin in injured hemisphere 24 and $72 \mathrm{~h}$ after CCI. Quantitative analysis of the expression of ZO-1 (C), Claudin-5 (D) and Occludin (E) in injured hemisphere. ${ }^{* *} \mathrm{p}<0.01$, TBI HMGB1 A-box group vs TBI Vehicle group, $n=3$ - 5 in each group. 
Fig. 3. Effects of HMGB1 A-box on brain edema, expression of AQP4 and MMPs in injured brain hemisphere after CCI. (A) The water content of injured and contralateral hemispheres was measured $1-72 \mathrm{~h}$ after CCI. ${ }^{* *} \mathrm{p}<0.01$, HMGB1 A-box (2 $\mathrm{mg} / \mathrm{Kg}$ ) groups are compared with their corresponding vehicle controls. (B) Representative pictures of western blot assay of AQP4 in the cortex 6 $48 \mathrm{~h}$ after CCI. (C) Quantitative analysis of AQP4 in the cortex. Optical densities of respective

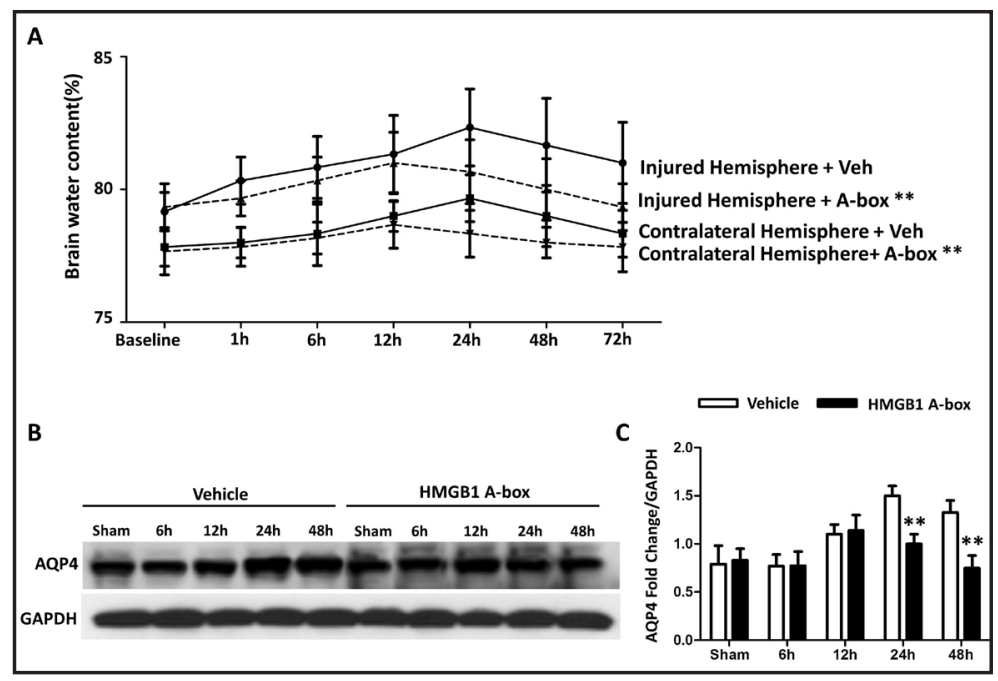
protein bands were analyzed with Quantity One (Bio-Rid) and normalized with loading control (GAPDH). ${ }^{* *} \mathrm{p}<0.01$, vs CCI vehicle group.

Fig. 3A, brain water content in TBI mice was significantly increased, compared with sham mice, however, it was significantly reduced by HMGB1 A-box treatment (Fig. $3 \mathrm{~A}$ ), to similar level as contralateral side $72 \mathrm{~h}$ after CCI (Fig. 3A). AQP4, an astrocytic water channel, is involved in brain edema formation. We found that HMGB1 A-box treatment significantly reduced AQP4 protein expression in injured hemisphere 24 and $48 \mathrm{~h}$ after CCI (Fig. 3B, C).

HMGB1 A-box reduced plasmalemma permeability

PI, a membrane impermeable fluorescent dye, was used to label injured cells after CCI. Plasmalemma permeability to PI occurred in injured cortex $24 \mathrm{~h}$ after CCI, however, HMGB1 A-box treatment significantly reduced the number of PI positive cells (Fig. 4A, B), suggesting that HMGB1 A-box treatment reduced plasmaemma permeability early (24 h) after CCI.

\section{HMGB1 A-box modulated cortical inflammation and MMPs in TBI}

Increased expression of the pro-inflammatory cytokines clinically correlates with the development of cerebral edema after brain injury [23]. Pro-inflammatory cytokines, such as TNF- $\alpha$, IL-1 $\beta$ and IL-6, were significantly increased in injured cortex of CCI plus vehicle mice compared with that in sham mice, as detected with ELISA $24 \mathrm{~h}$ after CCI (Fig. 5A, B, C). Matrix metalloproteinases (MMPs) are extracellular enzymes that have been implicated as key mediators in the BBB breakdown and brain edema after TBI [24]. Furthermore, the treatment of HMGB1 A-box inhibited the protein expressions of MMP-2 and MMP-9 (Fig. 5D, E). 
HMGB1 A-box reduced gene expressions in HMGB1/TLR4 pathway in primary astrocyte cultures

Extracellular HMGB1 is known to induce complex cascades of signaling via binding to its receptors, including RAGE, TLR2 and TLR4 [25]. We examined HMGB1 and TLR4 as well as their downstream cascades in primary astrocyte cultures to understand the cellular mechanisms underlying the inhibitory effects of HMGB1 A-box. As illustrated in Fig. 6A and $B$, administration of HMGB1 A-box attenuated the release of HMGB1 induced by IL-1 $\beta$ (10 $\mathrm{ng} / \mathrm{ml})$. Additionally, incubation with IL-1 $\beta(10 \mathrm{ng} / \mathrm{ml})$ for $24 \mathrm{~h}$ upregulated the expressions of TLR4, Myd88 and P65 in primary astrocyte cultures (Fig. 6A, C, D, E). IL-1 $\beta$-induced upregulation of these genes were attenuated by co-treatment with HMGB1 A-box (Fig. 6). These results indicated that the HMGB1-TLR4 inflammatory pathway was involved in the protective effects of HMGB1 A-box in TBI.

Fig. 5. HMGB1 A-box reduced brain inflammatory cytokines and MMPs. The level of TNF- $\alpha$ (A), IL-1 $\beta$ (B) and IL-6 (C) were tested at $24 \mathrm{~h}$ after TBI. $* * \mathrm{p}<0.01$, TBI HMGB1 A-box $(2$ $\mathrm{mg} / \mathrm{Kg}$ ) group vs TBI Vehicle group, $\mathrm{n}=3$ mice/group. (D) Analysis of MMP-2 and MMP-9 in injured hemisphere at $24 \mathrm{~h}$ after TBI with Western blot; (E) Semi-quantitative analysis of MMP-2 and MMP-9 protein expression in cortex. Optical densities of respective protein bands were analyzed with

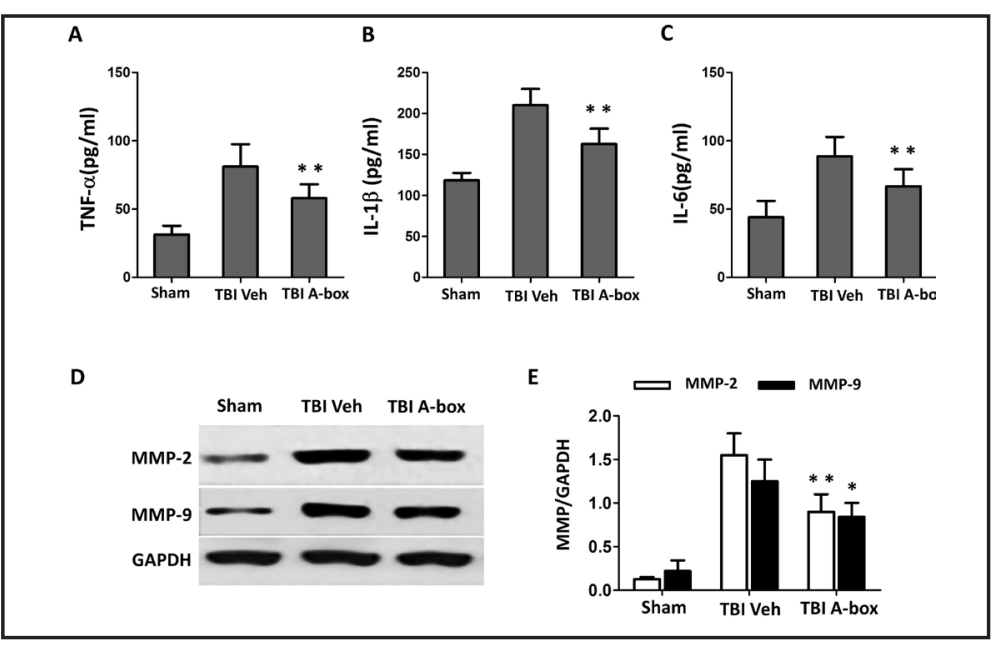
Quantity One (Bio-Rid) and normalized with loading control (GAPDH). ${ }^{* *} \mathrm{p}<0.01$, TBI HMGB1 A-box group vs TBI Vehicle group, $\mathrm{n}=3$ mice/group.

Fig. 6. Effects of HMGB1 A-box on HMGB1, TLR4, Myd88 and P65 in IL-1 $\beta$-stimulated astrocyte cultures. (A) Western blot assay of HMGB1, TLR4, Myd88 and p65 in astrocytes pretreated with HMGB1 A-box (500 ng/ml) and/or stimulated with IL-1b (10 ng/ml) for $24 \mathrm{~h}$; (B-E) Quantitative analysis of HMGB1, TLR4 and Myd88 levels in astrocytes. Optical densities of individual protein bands were analyzed with Quantity One (Bio-Rid) and normalized with loading control (Actin); ** $\mathrm{p}<0.01$, vs HMGB1 A-box / IL-1b+.

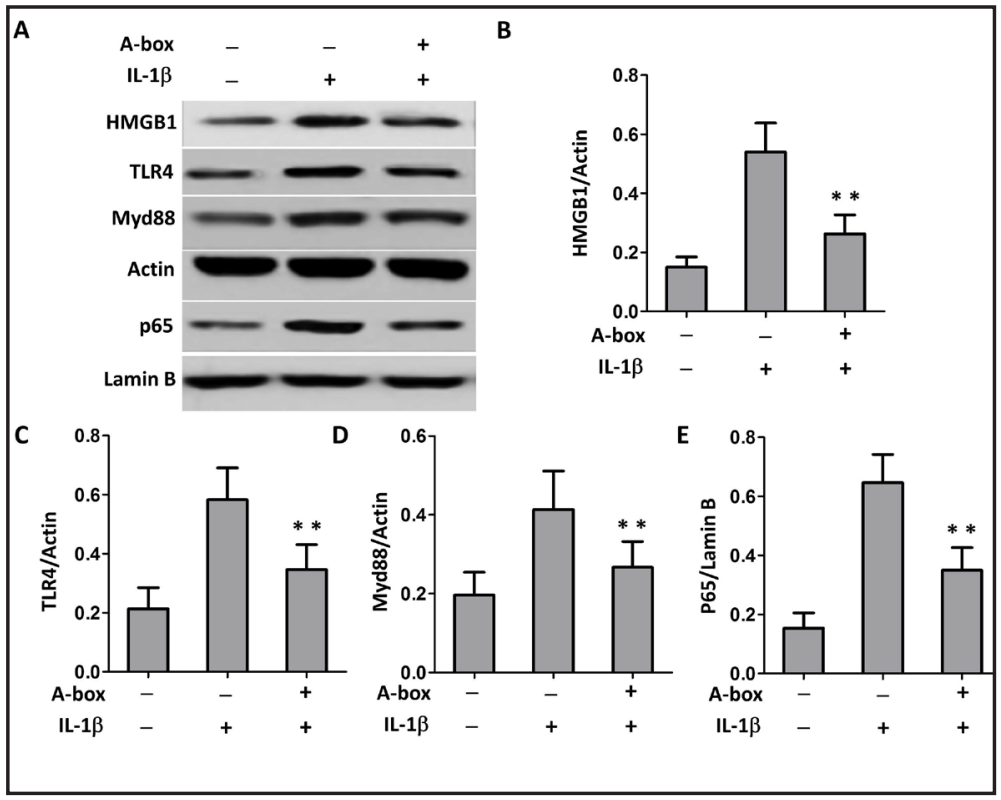




\section{Discussion}

In this study, we used a CCI model to mimic clinical TBI. We found that administration of HMGB1 A-box fragment, an N-terminal DNA binding domain of HMGB1, inhibited brain edema likely through protecting BBB and suppressing pro-inflammatory cytokines such as IL-1 $\beta$, IL- 6 and TNF- $\alpha$. As a result, HMGB1 A-box fragment reduced cell degeneration and improved neurological performance in TBI mice. In addition, HMGB1 A-box was shown to inhibit a pathway containing IL-1, HMGB1 and TLR/4 in astrocyte cultures. Overall, these findings suggest that treatment with HMGB1 A-box has neuroprotective effects on TBI mouse model.

TBI consists of primary and secondary injuries. The primary injury includes brain damage caused by an external force that results in structural damage and the disruption of the BBB. The secondary injury comprises the pathological processes including cerebral edema, elevated intracranial pressure, infection and neuronal death primarily due to inflammatory responses initiated by brain damage $[23,26]$. Interventions that inhibit the inflammatory responses may be useful to treat or prevent secondary damage, and improve the treatment outcome of TBI [23].

HMGB1 is a protein that exists in the cerebrospinal fluid and serum following brain injury in patients [27]. Its elevation is associated with the severity of brain damage following TBI [28]. Previous studies revealed that HMGB1 was translocated from the nucleus to the cytoplasm, and was released out of necrotic cells at early stages following TBI [9, 29]. These phenomena were robust between 1 and 7 days after TBI. Our experiments demonstrated that 1 to 7 days after CCI was the appropriate window of time to intervene brain damage, and HMGB1 A-box may have therapeutic potential to counteract brain damages following TBI.

HMGB1-targeting or direct binding represents a promising strategy to inhibit its inflammatory activities. Encouraging results, that have been obtained with HMGB1 antibodies, peptides, natural or synthetic molecules, suggest therapeutic effects of HMGB1 on TBI [27]. HMGB1-specific antibodies have been shown to reduce brain edema, decrease cell apoptosis and improve functional outcomes in intracerebral hemorrhage and TBI rat models $[8,30]$. Consistently, pharmacological inhibitors of HMGB1, glycyrrhizin and ethyl pyruvate, have beneficial effects in brain trauma models [31,32]. The HMGB1 A-box competes with the binding of the full-length protein, but does not activate its receptors $[10,33]$. Both in vitro and in vivo experiments showed that an enhanced anti-inflammatory activity was obtained by administration of HMGB1 A-box. Recombinant HMGB1 A-box peptide has been found to ameliorate the symptoms of collagen-induced arthritis [34] and angiogenesis [35]. Consistent with this notion, we provided evidence that HMGB1 A-box attenuated cerebral edema following TBI and improved overall behavioral outcomes in mice.

Microvascular hyperpermeability that occurs at the level of the BBB often leads to brain edema and elevates intracranial pressure following TBI [1]. Tight junction proteins (TJPs) between neighboring endothelial cells maintain the integrity of the BBB via TJPassociated proteins, particularly ZO-1, claudin-5 and Occludin [36]. Both immediate and delayed dysfunctions of the BBB were observed in TBI [36]. Moreover, the pro-inflammatory cytokine IL-1 $\beta$ and extracellular matrix proteins MMP-2/MMP-9 are key mediators of trauma-associated brain edema [24].

Consistent with this notion, we found that permeability of the BBB following CCI was significantly increased, as evidenced by increased penetration of Evans blue (Fig. 2). At the molecular level, the expression of ZO-1, claudin-5, Occludin and MMP-2/9 increased $24 \mathrm{~h}$ after CCI (Fig. 2). Administration of HMGB1 A-box reversed the elevation of those proteins in TBI mouse model, suggesting that HMGB1 A-box improved endothelial tight junctions and extracellular matrix, through which it may protect the BBB and prevent brain edema.

Besides inhibiting brain swelling, HMGB1 A-box also inhibited cellular swelling, as indicated by downregulation of AQP4 water channels which occurred within hours after CCI (Fig.3). In line with previous findings that HMGB1/TLR4 activation enhances the expression of AQP4 in astrocytes [37, 38], our data suggest that inhibition of astrocytic signaling 
pathways downstream of HMGB1 may be one of cellular mechanisms underlying protective effects of HMGB1 A-box against brain edema.

Inflammation, as an essential component of TBI, plays critical roles in the BBB breakdown, cell apoptosis and deterioration of neurobehavioral functions [23]. Numerous studies suggest that inhibition of cytokine activities by anti-inflammatory agents, including HMGB1 antibodies, could improve neurological functions in TBI [26, 30]. Administration of anti-inflammatory HMGB1 A-box shortly after injury inhibited IL-1 $\beta$, IL- 6 and TNF- $\alpha$ at $24 \mathrm{~h}$ following CCI (Fig. 5), suggesting that HMGB1 A-box has beneficial effects on early inflammation following TBI.

TLR4 and PAGE are two putative receptors for HMGB1 [9]. Increased expression of TLR4 and its downstream proteins Myd88 and P65, as well as HMGB1, were observed in IL-1 $\beta$ stimulated astrocyte cultures (Fig. 6). Interestingly, HMGB1 A-box attenuated expression of TLR4 and its downstream proteins in this system (Fig. 6). Although a functional modulation for TLR4 by HMGB1 A-box after TBI was not investigated in our study, taken together with previous report showing that in TBI, activation of HMGB1/TLR4 pathway in injured cortex was accompanied by development of edema [27, 37], our data indicate that inhibition of HMGB1/TLR4 pathway by HMGB1 A-box may mediate the protective effects on TBI.

In addition to the cellular and molecular effects of HMGB1 A-box on TBI, we also found that HMGB1 A-box gradually improved behavioral performance in the first week after CCI (Fig. 1). It is worth noting that the improvement of motor behaviors was apparent in the first 3 days (Fig. 1). The fast development of the behavioral effects of HMGB1 A-box is consistent with its cellular and molecular effects. This consistency hints on intimate relationships among the cellular, molecular and behavioral effects of HMGB1 A-box.

\section{Conclusion}

In conclusion, this study shows that TBI induces a cascade of events including BBB breakdown, brain edema, upregulation of TJPs, expression of inflammation related molecules. HMGB1 A-box treatment strongly inhibits these events, which may subsequently contribute to its improvement of neurological functions in TBI. Our data suggest that HMGB1 A-box may have therapeutic value for TBI.

\section{Acknowledgements}

This project is supported by Natural Science Foundation of Hebei Province, China (Grant No. H2015206201) and foundation of the Second Hospital of Hebei Medical University (Grant No. 2H2201510).

\section{Disclosure Statement}

The authors declare no conflict of interest.

\section{References}

1 Coles JP, Fryer TD, Smielewski P, Chatfield DA, Steiner LA, Johnston AJ, Downey SP, Williams GB, Aigbirhio F, Hutchinson PJ, Rice K, Carpenter TA, Clark JC, Pickard JD, Menon DK: Incidence and mechanisms of cerebral ischemia in early clinical head injury. J Cereb Blood Flow Metab 2004;24:202-211. 


\section{Cellular Physiology Cell Physiol Biochem 2018;46:2532-2542 \begin{tabular}{l|l} 
and Biochemistry Published onlIne: May II, 2018 & $\begin{array}{l}\text { C } 2018 \text { The Author(s). Published by S. Karger AG, Basel } \\
\text { www.karger.com/cpb }\end{array}$ \\
\hline
\end{tabular}}

Yang et al.: HMGB1 May Have Therapeutic Potential in TBI

2 Namjoshi DR, Good C, Cheng WH, Panenka W, Richards D, Cripton PA, Wellington CL: Towards clinical management of traumatic brain injury: a review of models and mechanisms from a biomechanical perspective. Dis Model Mech 2013;6:1325-1338.

-3 Keep RF, Hua Y, Xi G: Intracerebral haemorrhage: mechanisms of injury and therapeutic targets. Lancet Neurol 2012;11:720-731.

-4 Urday S, Kimberly WT, Beslow LA, Vortmeyer AO, Selim MH, Rosand J, Simard JM, Sheth KN: Targeting secondary injury in intracerebral haemorrhage--perihaematomal oedema. Nat Rev Neurol 2015;11:111122.

-5 Hutchinson PJ, O'Connell MT, Rothwell NJ, Hopkins SJ, Nortje J, Carpenter KL, Timofeev I, Al-Rawi PG, Menon DK, Pickard JD: Inflammation in human brain injury: intracerebral concentrations of IL-1alpha, IL-1beta, and their endogenous inhibitor IL-1ra. J Neurotrauma 2007;24:1545-1557.

6 Kimbler DE, Shields J, Yanasak N, Vender JR, Dhandapani KM: Activation of P2X7 promotes cerebral edema and neurological injury after traumatic brain injury in mice. PLoS One 2012;7:e41229.

7 Laird MD, Sukumari-Ramesh S, Swift AE, Meiler SE, Vender JR, Dhandapani KM: Curcumin attenuates cerebral edema following traumatic brain injury in mice: a possible role for aquaporin-4? J Neurochem 2010;113:637-648.

8 Wang D, Liu K, Wake H, Teshigawara K, Mori S, Nishibori M: Anti-high mobility group box-1 (HMGB1) antibody inhibits hemorrhage-induced brain injury and improved neurological deficits in rats. Sci Rep 2017;7:46243.

-9 Lotze MT, Tracey KJ: High-mobility group box 1 protein (HMGB1): nuclear weapon in the immune arsenal. Nat Rev Immunol 2005;5:331-342.

10 Li J, Kokkola R, Tabibzadeh S, Yang R, Ochani M, Qiang X, Harris HE, Czura CJ, Wang H, Ulloa L, Wang H, Warren HS, Moldawer LL, Fink MP, Andersson U, Tracey KJ, Yang H: Structural basis for the proinflammatory cytokine activity of high mobility group box 1. Mol Med 2003;9:37-45.

-11 LeBlanc PM, Doggett TA, Choi J, Hancock MA, Durocher Y, Frank F, Nagar B, Ferguson TA, Saleh M: An immunogenic peptide in the A-box of HMGB1 protein reverses apoptosis-induced tolerance through RAGE receptor. J Biol Chem 2014;289:7777-7786.

$>12$ Kong X, Yuan H, Wu X, Zhang J, Zhou H, Wang M, Liu Y, Jin X: High-mobility-group box protein 1A box reduces development of sodium laurate-induced thromboangiitis obliterans in rats. J Vasc Surg 2013;57:194-204.

13 Kline AE, Wagner AK, Westergom BP, Malena RR, Zafonte RD, Olsen AS, Sozda CN, Luthra P, Panda M, Cheng JP, Aslam HA: Acute treatment with the 5-HT(1A) receptor agonist 8-OH-DPAT and chronic environmental enrichment confer neurobehavioral benefit after experimental brain trauma. Behav Brain Res 2007;177:186-194.

14 Mahmood A, Goussev A, Lu D, Qu C, Xiong Y, Kazmi H, Chopp M: Long-lasting benefits after treatment of traumatic brain injury (TBI) in rats with combination therapy of marrow stromal cells (MSCs) and simvastatin. J Neurotrauma 2008;25:1441-1447.

15 Mbye LH, Keles E, Tao L, Zhang J, Chung J, Larvie M, Koppula R, Lo EH, Whalen MJ: Kollidon VA64, a membrane-resealing agent, reduces histopathology and improves functional outcome after controlled cortical impact in mice. J Cereb Blood Flow Metab 2012;32:515-524.

-16 Fox GB, Fan L, Levasseur RA, Faden AI: Sustained sensory/motor and cognitive deficits with neuronal apoptosis following controlled cortical impact brain injury in the mouse. J Neurotrauma 1998;15:599-614.

17 Weissman DE, Stewart C: Experimental drug therapy of peritumoral brain edema. J Neurooncol 1988;6:339342.

18 Whalen MJ, Dalkara T, You Z, Qiu J, Bermpohl D, Mehta N, Suter B, Bhide PG, Lo EH, Ericsson M, Moskowitz MA: Acute plasmalemma permeability and protracted clearance of injured cells after controlled cortical impact in mice. J Cereb Blood Flow Metab 2008;28:490-505.

19 Yang XF, Liu WG, Shen H, Gong JB, Yu J, Hu WW, Lu ST, Zheng XJ, Fu WM: Correlation of cell apoptosis with brain edema and elevated intracranial pressure in traumatic brain injury. Chin J Traumatol 2005;8:96-100.

20 Bierbach B, Meier M, Kasper-Konig W, Heimann A, Alessandri B, Horstick G, Oelert H, Kempski O: Emboli formation rather than inflammatory mediators are responsible for increased cerebral water content after conventional and assisted beating-heart myocardial revascularization in a porcine model. Stroke 2008;39:213-219. 


\section{Cellular Physiology Cell Physiol Biochem 2018;46:2532-2542 \begin{tabular}{ll|l} 
DOI: 10.1159/000489659 & Ond Biochemistry 2018 The Author(s). Published by S. Karger AG, Basel \\
wwww.karger.com/cpb
\end{tabular}

Yang et al.: HMGB1 May Have Therapeutic Potential in TBI

21 Zhou C, Luo ZD: Electrophysiological characterization of spinal neuron sensitization by elevated calcium channel alpha-2-delta-1 subunit protein. Eur J Pain 2014;18:649-658.

-22 Zhou C, Feng Z, Ko CP: Defects in Motoneuron-Astrocyte Interactions in Spinal Muscular Atrophy. J Neurosci 2016;36:2543-2553.

23 Corps KN, Roth TL, McGavern DB: Inflammation and neuroprotection in traumatic brain injury. JAMA Neurol 2015;72:355-362.

-24 Guilfoyle MR, Carpenter KL, Helmy A, Pickard JD, Menon DK, Hutchinson PJ: Matrix Metalloproteinase Expression in Contusional Traumatic Brain Injury: A Paired Microdialysis Study. J Neurotrauma 2015;32:1553-1559.

25 Maroso M, Balosso S, Ravizza T, Liu J, Aronica E, Iyer AM, Rossetti C, Molteni M, Casalgrandi M, Manfredi AA, Bianchi ME, Vezzani A: Toll-like receptor 4 and high-mobility group box-1 are involved in ictogenesis and can be targeted to reduce seizures. Nat Med 2010;16:413-419.

-26 Russo MV, McGavern DB: Inflammatory neuroprotection following traumatic brain injury. Science 2016;353:783-785.

27 Musumeci D, Roviello GN, Montesarchio D: An overview on HMGB1 inhibitors as potential therapeutic agents in HMGB1-related pathologies. Pharmacol Ther 2014;141:347-357.

28 Au AK, Aneja RK, Bell MJ, Bayir H, Feldman K, Adelson PD, Fink EL, Kochanek PM, Clark RS: Cerebrospinal fluid levels of high-mobility group box 1 and cytochrome $\mathrm{C}$ predict outcome after pediatric traumatic brain injury. J Neurotrauma 2012;29:2013-2021.

29 Gao TL, Yuan XT, Yang D, Dai HL, Wang WJ, Peng X, Shao HJ, Jin ZF, Fu ZJ: Expression of HMGB1 and RAGE in rat and human brains after traumatic brain injury. J Trauma Acute Care Surg 2012;72:643-649.

-30 Haruma J, Teshigawara K, Hishikawa T, Wang D, Liu K, Wake H, Mori S, Takahashi HK, Sugiu K, Date I, Nishibori M: Anti-high mobility group box-1 (HMGB1) antibody attenuates delayed cerebral vasospasm and brain injury after subarachnoid hemorrhage in rats. Sci Rep 2016;6:37755.

-31 Ohnishi M, Katsuki H, Fukutomi C, Takahashi M, Motomura M, Fukunaga M, Matsuoka Y, Isohama Y, Izumi Y, Kume T, Inoue A, Akaike A: HMGB1 inhibitor glycyrrhizin attenuates intracerebral hemorrhage-induced injury in rats. Neuropharmacology 2011;61:975-980.

32 Hidaka S, Iwasaka H, Hagiwara S, Noguchi T: Gabexate mesilate inhibits the expression of HMGB1 in lipopolysaccharide-induced acute lung injury. J Surg Res 2011;165:142-150.

33 Yang H, Ochani M, Li J, Qiang X, Tanovic M, Harris HE, Susarla SM, Ulloa L, Wang H, DiRaimo R, Czura CJ, Wang H, Roth J, Warren HS, Fink MP, Fenton MJ, Andersson U, Tracey KJ: Reversing established sepsis with antagonists of endogenous high-mobility group box 1. Proc Natl Acad Sci U S A 2004;101:296-301.

-34 Kokkola R, Li J, Sundberg E, Aveberger AC, Palmblad K, Yang H, Tracey KJ, Andersson U, Harris HE: Successful treatment of collagen-induced arthritis in mice and rats by targeting extracellular high mobility group box chromosomal protein 1 activity. Arthritis Rheum 2003;48:2052-2058.

-35 Zhang CL, Shu MG, Qi HW, Li LW: Inhibition of tumor angiogenesis by HMGB1 A box peptide. Med Hypotheses 2008;70:343-345.

-36 Chodobski A, Zink BJ, Szmydynger-Chodobska J: Blood-brain barrier pathophysiology in traumatic brain injury. Transl Stroke Res 2011;2:492-516.

-37 Laird MD, Shields JS, Sukumari-Ramesh S, Kimbler DE, Fessler RD, Shakir B, Youssef P, Yanasak N, Vender JR, Dhandapani KM: High mobility group box protein-1 promotes cerebral edema after traumatic brain injury via activation of toll-like receptor 4. Glia 2014;62:26-38.

-38 Ren Z, Iliff JJ, Yang L, Yang J, Chen X, Chen MJ, Giese RN, Wang B, Shi X, Nedergaard M: 'Hit \& Run' model of closed-skull traumatic brain injury (TBI) reveals complex patterns of post-traumatic AQP4 dysregulation. J Cereb Blood Flow Metab 2013;33:834-845. 